\title{
Programming effects of high-carbohydrate feeding of larvae on adult glucose metabolism in zebrafish, Danio rerio
}

\author{
Liu Fang ${ }^{1}$, Xu-Fang Liang ${ }^{1 *}$, Yi Zhou ${ }^{1}$, Xiao-Ze Guo ${ }^{1}$, Yan He ${ }^{1}$, Ti-Lin Yi ${ }^{1}$, Li-Wei Liu ${ }^{1}$, \\ Xiao-Chen Yuan ${ }^{1}$ and Ya-Xiong Tao ${ }^{2}$ \\ ${ }^{1}$ Key Lab of Freshwatder Animal Breeding, College of Fisheries, Ministry of Agriculture, Huazhong \\ Agricultural University, No. 1 Shizishan Street, Hongshan District, Wuban, Hubei 430070, People's Republic of China \\ ${ }^{2}$ Department of Anatomy, Physiology and Pharmacology, College of Veterinary Medicine, Auburn University, \\ Auburn, AL, USA
}

(Submitted 25 February 2013 - Final revision received 27 August 2013 - Accepted 30 August 2013 - First published online 11 October 2013)

\begin{abstract}
The aim of the present study was to determine the potential long-term metabolic effects of early nutritional programming on carbohydrate utilisation in adult zebrafish (Danio rerio). High-carbohydrate diets were fed to fish during four ontogenetic stages: from the firstfeeding stage to the end of the yolk-sac larval stage; from the first-feeding stage to $2 \mathrm{~d}$ after yolk-sac exhaustion; after yolk-sac exhaustion for 3 or $5 \mathrm{~d}$. The carbohydrate stimuli significantly increased the body weight of the first-feeding groups in the short term. The expression of genes was differentially regulated by the early dietary intervention. The high-carbohydrate diets resulted in decreased plasma glucose levels in the adult fish. The mRNA levels and enzyme activities of glucokinase, pyruvate kinase, $\alpha$-amylase and sodium-dependent glucose co-transporter 1 were up-regulated in the first-feeding groups. There was no significant change in the mRNA levels of glucose-6-phosphatase (G6Pase) in any experimental group, and the activity of G6Pase enzyme in the FF-5 (first feeding to $2 \mathrm{~d}$ after yolk-sac exhaustion) group was significantly different from that of the other groups. The expression of phosphoenolpyruvate carboxykinase gene in all the groups was significantly decreased. In the examined early programming range, growth performance was not affected. Taken together, data reported herein indicate that the period ranging from the polyculture to the external feeding stage is an important window for potential modification of the long-term physiological functions. In conclusion, the present study demonstrates that it is possible to permanently modify carbohydrate digestion, transport and metabolism of adult zebrafish through early nutritional programming.
\end{abstract}

Key words: First feeding: Early nutritional programming: Carbohydrate diets: Glucose metabolism: Zebrafish

The use of carbohydrates as digestible energy sources in fish diets bears economic significance in aquaculture industry ${ }^{(1)}$. Diets that contain digestible carbohydrates can promote rapid growth and provide metabolic intermediates for the synthesis of other biologically important compounds ${ }^{(2,3)}$. When carbohydrates are not provided in feedstuffs, more proteins are catabolised for energy and for the synthesis of glucose, which impairs protein retention and increases $\mathrm{N}$ excretion into the environment ${ }^{(1,4)}$. Therefore, it is important to provide an appropriate amount of carbohydrates in fish diets. However, the mechanisms of carbohydrate digestion, absorption and metabolism are different among different fish species; that is, omnivorous or herbivorous fish can utilise higher amounts of dietary carbohydrates and exhibit a greater degree of protein sparing $^{(5-7)}$, whereas carnivorous fish species have a relatively low ability to utilise carbohydrates ${ }^{(8)}$.

The liver plays an important role in the coordination of whole-body metabolic functions in response to nutritional status. Specifically, in conjunction with the gastrointestinal tract, the liver plays a major role in glucose metabolism including gluconeogenesis and glycolysis. Most of the knowledge on these metabolic processes comes from studies in mammals. However, in fish, glucose does not appear to have the same effects on metabolism ${ }^{(9)}$. Correspondingly, the dietary regulation of gluconeogenic and glycolytic gene expression and activity in relation to carbohydrate utilisation in fish appears to be influenced by the potential variation in carbohydrate supply. For example, induction of both gene expression and

Abbreviations: AMY, $\alpha$-amylase; FF-3, fish fed the $60 \% \mathrm{MD}$ diet from the first-feeding stage to the end of the yolk-sac larval stage; FF-5, fish fed the $60 \% \mathrm{MD}$ diet from the first-feeding stage to $2 \mathrm{~d}$ after yolk-sac exhaustion; G6Pase, glucose-6-phosphatase; GK, glucokinase; MD, maltodextrin; PEPCK, phosphoenolpyruvate carboxykinase; PK, pyruvate kinase; SGLT-1, sodium-dependent glucose co-transporter 1; YE-3, fish fed the 60\%MD diet after yolk-sac exhaustion for $3 \mathrm{~d}$; YE-5, fish fed the $60 \%$ MD diet after yolk-sac exhaustion for $5 \mathrm{~d}$. 
enzyme activity of glucokinase (GK) by high dietary carbohydrates ( $>20 \%$ digestible starch) has been observed in the liver of rainbow trout (Oncorbynchus mykiss), gilthead seabream (Sparus aurata) and common carp (Cyprinus carpio $)^{(10)}$. Pyruvate kinase (PK) is a key glycolytic enzyme that catalyses the last step in glycolysis ${ }^{(11)}$. The activity and gene expression of $\mathrm{PK}$ in the liver have been reported to decrease during starvation or diabetes and increase as a result of high-carbohydrate feeding or insulin administration ${ }^{(12)}$. Dietary carbohydrates have been shown to have no significant effects on the expression and activity of phosphoenolpyruvate carboxykinase (PEPCK) and glucose-6-phosphatase (G6Pase) in the liver of rainbow trout ${ }^{(13)}$.

Gut is also an important organ involved in digestion and absorption. Different nutrients can affect the regulation of gastrointestinal tract gene expression and enzyme activity. Na-dependent glucose co-transporter 1 (SGLT-1) plays an important role in glucose absorption and homeostasis. Short-term feeding with a highstarch diet has been shown to improve intestinal glucose absorption and SGLT-1 activity and protein density in mice ${ }^{(14)}$. High-carbohydrate diets, compared with carbohydrate-free diets, have been reported to increase the expression of SGLT-1 gene in the intestine of trout ${ }^{(13)}$. Increased dietary starch content has been shown to enhance the activity of amylase but not affect its mRNA levels in sea bass larvae ${ }^{(15)}$. The expression of maltase gene has been reported to be higher in juvenile rainbow trout that experienced a hyperglucidic stimulus in the larval stages than in the control fish in the glucose loading test ${ }^{(16)}$.

Evidence for nutritional programming has been established in animals, in which brief pre- or postnatal nutritional manipulations may programme adult size, metabolism, blood lipids, blood pressure, obesity, atherosclerosis, learning, behaviour and lifespan ${ }^{(17)}$. However, there is limited information about the effects of early nutritional programming in fish. Recently, zebrafish has been proposed as a possible model for nutrition and growth studies and nutritional genomics in fish ${ }^{(18-20)}$. Therefore, in the present study, we used zebrafish as a model to determine potential long-term persistent metabolic changes in carbohydrate utilisation in adult zebrafish through early nutritional programming (feeding high-carbohydrate diets) during an early sensitive period. As early highcarbohydrate programming phases, four ontogenetic stages, from the first-feeding stage to the end of the yolk-sac larval stage (FF-3), from the first-feeding stage to $2 \mathrm{~d}$ after yolk-sac exhaustion (FF-5), and after yolk-sac exhaustion for 3 or $5 \mathrm{~d}$ (YE-3 or YE-5), were chosen. Fish were fed high-carbohydrate diets during these stages. We assessed growth, blood glucose levels, and hepatic and intestinal gene expression and activities of enzymes in an attempt to obtain insights into the pattern of carbohydrate digestion, transport and metabolism through early nutritional programming.

\section{Materials and methods}

\section{Preparation of experimental diets and feeding scheme}

In the present study, two laboratory-prepared diets and one commercially available diet were used. The experimental diets were prepared in the College of Fisheries at Huazhong Agricultural University, Wuhan, China. Maltodextrin (MD) obtained from the Gao Long Dietary Company (Wuhan, China) was used as the carbohydrate source. The ingredients were ground into a fine powder through a $320 \mu \mathrm{m}$ mesh. All the ingredients were thoroughly mixed with fish oil, and water was added to obtain stiff dough. The dough was then pelleted and dried for about $12 \mathrm{~h}$ in a ventilated oven at $60^{\circ} \mathrm{C}$. After drying, the pellets were broken up, sieved into a proper size and stored at $-20^{\circ} \mathrm{C}$ until use. The commercial zebrafish diet was purchased from Beijing New Rainbow Feed Industries Company Limited, Beijing, China. The ingredient formulation and proximate chemical composition of the experimental diets and commercial diet are given in Table 1.

The zebrafish were fed a $60 \% \mathrm{MD}$ diet at four ontogenetic stages: the first-feeding $3 \mathrm{~d}$ period ( $\mathrm{FF}-3$, from the first-feeding stage to the end of the yolk-sac larval stage); the first-feeding $5 \mathrm{~d}$ period ( $\mathrm{FF}-5$, from the first-feeding stage to $2 \mathrm{~d}$ after yolksac exhaustion); after yolk-sac exhaustion for 3 or $5 \mathrm{~d}$ (YE-3 or YE-5) as early high-carbohydrate programming phases. A $35 \% \mathrm{MD}$ diet was fed to adult fish for 1 week as the final challenge test to determine the effect of early nutritional programming. Before and after being fed the $60 \% \mathrm{MD}$ diet, the fish were fed the commercial zebrafish diet until the adult stage. The control group was fed the commercial diet from the beginning of the first-feeding stage to the final challenge test. During the high-carbohydrate dietary programming period, feed was manually distributed six times daily to visual satiety from 08.00 to 18.00 hours and thereafter two times daily at 09.00 and 16.00 hours for the rest of the experimental period. The feeding regimen is summarised in Table 2 .

Table 1. Ingredient formulation and proximate chemical composition of the experimental diets and commercial diet

\begin{tabular}{|c|c|c|c|}
\hline \multirow[b]{2}{*}{ Components } & \multirow[b]{2}{*}{ Control diet ${ }^{\star}$} & \multicolumn{2}{|c|}{ MD inclusion level } \\
\hline & & $35 \% \mathrm{MD} \dagger$ & $60 \% \mathrm{MD} \dagger$ \\
\hline \multicolumn{4}{|l|}{ Ingredient formulation (\%) } \\
\hline Fishmeal & & 60 & 35 \\
\hline Fish oil & & 5 & 5 \\
\hline Mineral mix $\ddagger$ & & 1 & 1 \\
\hline Vitamin mix§ & & 1 & 1 \\
\hline MD & & 35 & 60 \\
\hline Alginate & & 1 & 1 \\
\hline \multicolumn{4}{|l|}{ Chemical composition } \\
\hline DM (\%) & $95 \cdot 80$ & 95.45 & 95.64 \\
\hline Crude protein (\%DM) & $53 \cdot 11$ & $48 \cdot 27$ & $31 \cdot 87$ \\
\hline Crude fat (\%DM) & $15 \cdot 59$ & $10 \cdot 20$ & $10 \cdot 64$ \\
\hline Ash (\%DM) & $10 \cdot 77$ & $17 \cdot 26$ & 8.03 \\
\hline Carbohydrate\| & $20 \cdot 53$ & $24 \cdot 27$ & 49.46 \\
\hline
\end{tabular}

MD, maltodextrin.

${ }^{*}$ A commercial zebrafish diet (Beijing New Rainbow Feed Industries Company Limited).

† $35 \% \mathrm{MD}$ : diet containing 35\%MD; 60\%MD: diet containing $60 \% \mathrm{MD}$; MD was obtained from the Gao Long Dietary Company.

‡ Mineral premix (mg/kg diet): $\mathrm{NaCl}, 0.80 ; \mathrm{MgSO}_{4} .7 \mathrm{H}_{2} \mathrm{O}, 12 ; \mathrm{NaH}_{2} \mathrm{PO}_{4} .2 \mathrm{H}_{2} \mathrm{O}, 20$ $\mathrm{KH}_{2} \mathrm{PO}_{4}, 25.6 ; \mathrm{Ca}\left(\mathrm{H}_{2} \mathrm{PO}_{4}\right)_{2} . \mathrm{H}_{2} \mathrm{O}, 16 ; \mathrm{FeSO} 4.5 \mathrm{H}_{2} \mathrm{O}, 2 ;\left(\mathrm{CH}_{2} \mathrm{CHCOO}\right)_{2} \mathrm{Ca} .5 \mathrm{H}_{2} \mathrm{O}$ 2.8; $\mathrm{ZnSO}_{4} .7 \mathrm{H}_{2} \mathrm{O}, \quad 0.028 ; \mathrm{MnSO}_{4} .4 \mathrm{H}_{2} \mathrm{O}, \quad 0.013 ; \quad \mathrm{CuSO} 4.5 \mathrm{H}_{2} \mathrm{O}, 0.0025$ $\mathrm{CoCl} 2.6 \mathrm{H}_{2} \mathrm{O}, 0.0008 ; \mathrm{KIO}_{3}, 0.0024$; cellulose, 0.36 (Gao Long Dietary Company).

$\S$ Vitamin premix (mg/kg diet): vitamin A, 1.83; vitamin D, 0.5; vitamin E, 10; vitamin $\mathrm{K}, 10$; niacin, 100; riboflavin, 20; pyridoxine, 20; thiamin, 20; D-calcium pantothenate, 50; biotin, 1.0; folic acid, 5; vitamin $\mathrm{B}_{12}$, 2; ascorbic acid, 100; inositol, 100 (Gao Long Dietary Company).

$\|$ Carbohydrate $=1-$ (crude protein+crude fat+ash) 
Table 2. Feeding regimen followed in the experiment

\begin{tabular}{llllll}
\hline & \multicolumn{4}{c}{ First trial period } & Final challenge \\
\cline { 2 - 5 } Treatments & $3-5 \mathrm{dph}$ & $6-8 \mathrm{dph}$ & $9-10 \mathrm{dph}$ & $11 \mathrm{dph}-15$ th week & 16th week \\
\hline Control group & Control diet & Control diet & Control diet & Control diet & $35 \% \mathrm{MD}$ \\
FF-3 & $60 \% \mathrm{MD}$ & Control diet & Control diet & Control diet & $35 \% \mathrm{MD}$ \\
FF-5 & $60 \% \mathrm{MD}$ & $60 \% \mathrm{MD}$ & Control diet & Control diet & $35 \% \mathrm{MD}$ \\
YE-3 & Control diet & $60 \% \mathrm{MD}$ & Control diet & Control diet & $35 \% \mathrm{MD}$ \\
YE-5 & Control diet & $60 \% \mathrm{MD}$ & $60 \% \mathrm{MD}$ & Control diet & $35 \% \mathrm{MD}$ \\
\hline
\end{tabular}

dph, days post-hatching; MD, maltodextrin; FF-3, fish fed the $60 \% \mathrm{MD}$ diet from the first-feeding stage to the end of the yolk-sac larval stage; FF-5, fish fed the $60 \% \mathrm{MD}$ diet from the first-feeding stage to $2 \mathrm{~d}$ after yolk-sac exhaustion; YE-3, fish fed the $60 \% \mathrm{MD}$ diet after yolk-sac exhaustion for $3 \mathrm{~d}$; YE-5, fish fed the $60 \% \mathrm{MD}$ diet after yolk-sac exhaustion for $5 \mathrm{~d}$.

\section{Fish-rearing conditions and sampling}

Zebrafish (ripe fish) were obtained from the Institute of Hydrobiology, Chinese Academy of Sciences (Wuhan, China), and reared with artemia before fertilisation. Fish larvae were transferred to an indoor filtered recirculating culture system (Shanghai Haisheng Aquarium Facility Manufactory) 6d after hatching ${ }^{(21,22)}$, where only respiratory gases and heat were allowed to exchange freely via 150-lam screen mesh filters. The capacity of each tank was $10 \cdot 3$ litres $(25 \mathrm{~L} \times 20 \mathrm{~W} \times 18 \mathrm{H} \mathrm{cm})$, with each tank having 200 larvae. The five experimental groups were randomly assigned to the tanks with three replicate ( $n 200$ fish per tank) per dietary treatment for 16 weeks. Initial stocking density was 200 fish per tank (twenty fish per litre). When the total length of the fish reached $10 \mathrm{~mm}$, some were removed to decrease the density to 100 fish per tank (10/litre). The flow rate with sufficient aeration was $1.33-1.50 \mathrm{l} / \mathrm{min}$. Photoperiod was set at $14 \mathrm{~h} \mathrm{light}-10 \mathrm{~h}$ dark by microcomputer timer switch. Temperature was maintained at $28 \pm 0.5^{\circ} \mathrm{C}$ and $\mathrm{pH}$ at $7 \cdot 53-7 \cdot 70$. The concentrations of $\mathrm{NH}_{3}, \mathrm{NO}^{2-}$ and $\mathrm{NO}^{3-}$ were $<0 \cdot 1 \mathrm{mg} / \mathrm{l}$.

At the end of the early high-carbohydrate programming period, fifteen fish were randomly sampled from each tank to measure body weight (collectively weighed to calculate their average body weight) and length (using an Olympus LG-SP2 stereoscopic microscope, SZX2-FOF 9J01021). The whole bodies of larvae were quickly frozen in liquid $\mathrm{N}_{2}$ and stored at $-80^{\circ} \mathrm{C}$ until molecular analyses. At the end of the feeding experiment, the adult zebrafish were large enough for collecting samples of individual tissues. The fish were sampled $3 \mathrm{~h}$ after being fed the last meal. The fish were anaesthetised with tricaine methanesulfonate (Sigma) and body length and weight were measured. Then, the fish were patted dry with filter paper and placed on a glass surface. Blood was sampled at the caudal vein to measure plasma glucose levels using a blood glucose monitor (Accu-Chek Performa, Roche). For each group, three readings were taken. The liver and intestinal tissue samples were quickly frozen in liquid $\mathrm{N}_{2}$ and stored at $-80^{\circ} \mathrm{C}$ until analyses. The animal experimental procedures were in compliance with Huazhong Agricultural University Ethics Committee's Code of Practice for the Care and Use of Animals for Scientific Purposes. In the present experiment, there were no aspects that caused aggravation or unnecessary harm or stress to the fish.

\section{Assessment of enzyme activities}

For assaying the activities of enzymes involved in protein metabolism, crude extracts of liver were obtained by homogenisation of frozen tissue in ice-cold $0.7 \%$ saltwater. Following centrifugation $\left(3200 \mathrm{~g}\right.$ for $20 \mathrm{~min}$ at $\left.4{ }^{\circ} \mathrm{C}\right)$, the activities of enzymes were determined using a microplate reader (SPECTRAFluor; Tecan) and microplates. The activities of GK (EC 2.7.1.2), G6Pase (EC 3.1.3.9) and PK (EC 2.7.1.40) were estimated as described previously ${ }^{(23)}$. The activities of PEPCK (EC 4.1.1.32) and $\alpha$-amylase (AMY, EC 3.2.1.1) were determined as described previously ${ }^{(24,25)}$.

\section{Gene expression analysis by real-time quantitative RT-PCR}

Total RNA was extracted using the TRIzol reagent (Invitrogen), treated with RQI RNase-free DNase (Takara) to remove DNA contaminants and then spectrophotometrically quantified using a UV-vis spectrophotometer (Nanodrop ND-1000, Thermo Fisher Scientific). Optical density (OD) A260:A280 ratios were 1.8-2.0 and $\mathrm{OD} 260: 230$ ratios were $>1 \cdot 8$. For each RT reaction, $2 \mu \mathrm{g}$ of RNA were subjected to complementary DNA synthesis using the SuperScript ${ }^{\mathrm{TM}}$ II Reverse Transcriptase (Takara) according to the manufacturer's instructions. The primers of the selected genes used in the real-time PCR are listed in Table 3. Relative quantification of the target gene transcripts was done using $\beta$-actin gene as the reference ${ }^{(26)}$, which was stably expressed in the present experiment. After the final PCR cycle, melting curves were systematically monitored $\left(55^{\circ} \mathrm{C}\right.$ temperature gradient at $0.5^{\circ} \mathrm{C} / \mathrm{s}$ from 55 to $94^{\circ} \mathrm{C}$ ) to ensure that only one fragment was amplified. Real-time PCR was carried out using a quantitative thermal cycler (Bio-Rad CFX96, Bio-Rad) with the SYBR Green Real Time PCR Master Mix (Takara) according to the manufacturer's recommendations. The PCR parameters were forty cycles at $95^{\circ} \mathrm{C}$ for $15 \mathrm{~s}, 60^{\circ} \mathrm{C}$ for $15 \mathrm{~s}$ and $72^{\circ} \mathrm{C}$ for $45 \mathrm{~s}$, with an additional initial $1 \mathrm{~min}$ denaturation step at $95^{\circ} \mathrm{C}$. Pooled complementary DNA samples of the respective tissues were used to generate the calibration curves. The amplification efficiencies of the control and target genes were approximately equal and ranged from 95.4 to $101.1 \%$. The expression of the genes was quantified relative to that of $\beta$-actin using the optimised comparative $C_{\mathrm{t}}\left(2^{-\Delta \Delta C_{\mathrm{t}}}\right)$ value method ${ }^{(27)}$. All amplifications were carried out in triplicate for each RNA sample. 
Table 3. List of primers used in the quantitative real-time PCR

\begin{tabular}{|c|c|c|}
\hline Primer names & Primer sequences & Accession no. \\
\hline$\beta$-Actin & $\begin{array}{l}\text { F: 5'-CACCTTCCAGCAGATGTGGA-3' } \\
\text { R: 5'-AAAAGCCATGCCAATGTTGTC-3' }\end{array}$ & NM_131031 \\
\hline GK & $\begin{array}{l}\text { F: 5'-TATGATAAAGCGGTCCCA-3' } \\
\text { R: 5'-CTCCAAGCCTCCCAAAAC-3' }\end{array}$ & NM_001045385 \\
\hline$P K$ & $\begin{array}{l}\text { F: 5'-AGAAACAGCCAAAGGACA-3' } \\
\text { R: 5'-ACGAGGACGATAACGAGA-3' }\end{array}$ & BC152219 \\
\hline G6Pase & $\begin{array}{l}\text { F: 5'-GGCTGAACCTCGTCCTAAAGT-3' } \\
\text { R: 5'-GATTGAAAGCAACGCTGTGAT-3' }\end{array}$ & BC076446 \\
\hline PEPCK & $\begin{array}{l}\text { F: 5'-CGGAGTGTTTGTAGGG-3' } \\
\text { R: 5'-GTGGAAGATTTTGGGC-3' }\end{array}$ & NM_214751 \\
\hline$A M Y$ & $\begin{array}{l}\text { F: 5'-TTGGAGAAGGACTATGTGCGCAGT-3' } \\
\text { R: 5'-ACCACCGAGTGTTGAGATTGTGGA-3' }\end{array}$ & NM_213011 \\
\hline$S G L T-1$ & $\begin{array}{l}\text { F: 5'-TAAAGCTGTCTGTGGAGCCGAAGT-3' } \\
\text { R: 5'-ACAACATCAACCCTCGGAGACCAT-3' }\end{array}$ & NM_200681 \\
\hline
\end{tabular}

\section{Statistical analyses}

All the statistical analyses were carried out using the SPSS 17.0 program for Windows (SPSS Inc.). Data are presented as means with their standard errors. The means within each treatment group and among the treatment groups were subjected to one-way ANOVA followed by Duncan's multiple range tests. The normality of data was assessed with the Shapiro-Wilk test using the SPSS software, and all the data were normally distributed. The data were also tested for homogeneity using SPSS, and $P$ values were greater than the $\alpha$-level in the homogeneity of variance test ${ }^{(28)}$.

\section{Results}

Short- and long-term effects of early dietary carbohydrate manipulation on growth performance

Significant effects of early dietary carbohydrate manipulation were observed on the body weight and length of the fish, as

Table 4. Growth performance of zebrafish during the early stages

(Mean values with their standard errors)

\begin{tabular}{|c|c|c|c|c|}
\hline \multirow[b]{2}{*}{ Treatments } & \multicolumn{2}{|c|}{ Control group } & \multicolumn{2}{|c|}{$\begin{array}{l}\text { Experimental } \\
\text { group }\end{array}$} \\
\hline & Mean & SE & Mean & SE \\
\hline \multicolumn{5}{|l|}{ FF-3 } \\
\hline Wet weight ${ }^{\star}(\mathrm{mg})$ & 0.66 & 1.50 & & \\
\hline Total length $(\mathrm{mm})$ & 4.57 & 0.05 & 4.44 & 0.05 \\
\hline \multicolumn{5}{|l|}{ FF-5 } \\
\hline Wet weight (mg) & 0.70 & 0.90 & & \\
\hline Total length $(\mathrm{mm})$ & $5 \cdot 24$ & 0.08 & 4.46 & 0.09 \\
\hline \multicolumn{5}{|l|}{ YE-3 } \\
\hline Wet weight (mg) & 0.93 & 0.69 & & \\
\hline Total length $(\mathrm{mm})$ & $5 \cdot 38$ & 0.09 & 4.49 & 0.13 \\
\hline \multicolumn{5}{|l|}{ YE-5 } \\
\hline Wet weight (mg) & 1.55 & 0.53 & & \\
\hline Total length $(\mathrm{mm})$ & $6 \cdot 28$ & 0.06 & 4.71 & 0.11 \\
\hline
\end{tabular}

FF-3, fish fed the $60 \%$ maltodextrin $(60 \% \mathrm{MD})$ diet from the first-feeding stage to the end of the yolk-sac larval stage; FF-5, fish fed the $60 \% \mathrm{MD}$ diet from the first-feeding stage to $2 \mathrm{~d}$ after yolk-sac exhaustion; YE-3, fish fed the $60 \% \mathrm{MD}$ diet after yolk-sac exhaustion for $3 \mathrm{~d}$; YE-5, fish fed the $60 \% \mathrm{MD}$ diet after yolk-sac exhaustion for $5 \mathrm{~d}$.

* Due to small size, the mean weight was used. indicated by the mean weight and individual length data given in Table 4. In the FF-3 period, significant differences in growth were observed between the four groups. At the end of the FF-3 and FF-5 periods, the larvae (1.50 (SE 0.02) and $0.90(\mathrm{se} 0.04) \mathrm{mg}$ ) were significantly heavier than those of the control group (0.66 (SE 0.05) and 0.70 (SE 0.05) mg). However, at the end of the YE- 3 and YE- 5 periods, the inverse was observed: the FF-3 and FF-5 larvae (0.69 (SE 0.05) and 0.53 (SE 0.05$) \mathrm{mg}$ ) had a lower body weight than those of the control group (0.93 (SE 0.04) and 1.55 (SE 0.02) mg). Compared with the corresponding developmental stages of the control group, the experimental groups were shorter in body length. As expected, the body weight and length of the control group increased gradually with the progression of the experiment. The final body weight of the four experimental groups was not different from that of the control group. Although not significant, the body length of the firstfeeding groups was shorter than that of the control group. Condition index was significantly increased in the FF-5 group (Table 5).

\section{Gene expression in the larval stages}

The effects of short-term dietary carbohydrate manipulation on the expression of six genes, including GK, PK, PEPCK, G6Pase, $A M Y$ and $S G L T-1$, in the larval stages are shown in Fig. 1. The expression of all the genes, except $P K$ gene, in the larvae of the FF-3 group was up-regulated compared with that in the larvae of the control group fed the commercial diet (Fig. 1(A)). In the FF-5 group, the expression of only $G K$ gene was significantly increased. The expression of PK, PEPCK, G6Pase and $S G L T-1$ genes was significantly down-regulated, while the mRNA levels of $A M Y$ did not change significantly (Fig. 1(B)). After yolk-sac exhaustion, the expression of SGLT-1 gene was significantly higher in the larvae of the YE-3 group than in those of the control group; the expression of other genes was significantly down-regulated, except that of $G K$ (Fig. 1(C)). The expression of $G K$ gene in the FE- 5 group was up to 14-fold greater than that in the control group and that of $A M Y$ gene was also up-regulated. The expression of PEPCK and $S G L T-1$ genes remained unaltered. The mRNA levels of $P K$ 
Table 5. Growth performance and plasma glucose levels (mM) of adult zebrafish

(Mean values with their standard errors)

\begin{tabular}{|c|c|c|c|c|c|c|c|c|c|c|}
\hline & \multicolumn{2}{|c|}{ Control group } & \multicolumn{2}{|c|}{ FF-3 } & \multicolumn{2}{|c|}{ FF-5 } & \multicolumn{2}{|c|}{ YE-3 } & \multicolumn{2}{|c|}{ YE-5 } \\
\hline & Mean & SE & Mean & SE & Mean & SE & Mean & SE & Mean & SE \\
\hline Body weight (mg) & 165.00 & $27 \cdot 83$ & 118.00 & $10 \cdot 67$ & 152 & $26 \cdot 34$ & 145 & 14.43 & 150 & 11.55 \\
\hline Body length (mm) & $25 \cdot 70^{a, b}$ & 0.94 & $23 \cdot 66^{a}$ & 0.64 & $23 \cdot 92^{a, b}$ & 1.39 & $25 \cdot 67^{a, b}$ & 0.03 & $26 \cdot 97^{\mathrm{b}}$ & 0.08 \\
\hline Condition index* & $0.94^{\mathrm{a}}$ & 0.08 & $0.89^{\mathrm{a}}$ & 0.08 & $1 \cdot 23^{\mathrm{b}}$ & 0.03 & $0.86^{\mathrm{a}}$ & 0.08 & $0.76^{a}$ & 0.05 \\
\hline Glucose level (mM) & $2 \cdot 20^{b}$ & 0.22 & $1 \cdot 80^{\mathrm{a}, \mathrm{b}}$ & 0.06 & $1.60^{\mathrm{a}}$ & 0.12 & $1.40^{\mathrm{a}}$ & 0.15 & $1 \cdot 83^{a, b}$ & 0.18 \\
\hline
\end{tabular}

Control group, fish fed the commercial diet; FF-3, fish fed the $60 \%$ maltodextrin diet from the first-feeding stage to the end of the yolk-sac larval stage; FF-5, fish fed the $60 \%$ maltodextrin diet from the first-feeding stage to $2 \mathrm{~d}$ after yolk-sac exhaustion; YE-3, fish fed the $60 \%$ maltodextrin diet after yolk-sac exhaustion for $3 \mathrm{~d}$; YE-5, fish fed the $60 \%$ maltodextrin diet after yolk-sac exhaustion for $5 \mathrm{~d}$.

${ }^{\mathrm{a}, \mathrm{b}}$ Mean values within a row with unlike superscript letters were significantly different $(P<0 \cdot 05$; one-way ANOVA and Duncan's multiple range tests).

${ }^{*}$ Condition index $=$ body weight $(\mathrm{mg}) /$ length $(\mathrm{mm})^{3} \times 100$.

and G6Pase in the YE-5 group were lower than those in the control group (Fig. 1(D)).

\section{Plasma glucose levels, hepatic and intestinal enzyme} activities and metabolite levels in adult zebrafish

The plasma glucose levels of the adult zebrafish are summarised in Table 5. Compared with those of the control group $(2.2 \mathrm{~mm})$, the plasma glucose levels of the four treatment groups exhibited various degrees of decline, ranging from 1.4 to $2.2 \mathrm{~mm}$, with the levels of the FF- 5 and YE-3 groups being significantly lower than those of the control group.

Gene expression and enzyme activities in the liver and intestine of adult zebrafish subjected to the final challenge test with the 35\%MD diet are shown in Figs. 2 and 3, respectively. After the final challenge test, the transcript levels of the six key genes involved in carbohydrate digestion, transport and metabolism were determined in the adult fish (Fig. 2). The hepatic mRNA levels of $G K$ in the FF-3 group were increased. The hepatic mRNA levels of $P K$ in the FF- 5 group were higher than those in the control group. The hepatic mRNA levels of G6Pase in the four treatment groups were not significantly different from those in the control group; however, all the four treatment groups had significantly lower mRNA levels of PEPCK than the control group. The expression of $A M Y$ gene in the adult fish of the FF-3 group was higher than that in the adult fish of the other four groups. The expression of SGLT-1 gene in the FF-3 and FF-5 groups was higher and that in the YE-3 and YE-5 groups was lower than that in the control group.

The activities of GK and PK (Fig. 3(A) and (B)) were significantly altered by early high-carbohydrate feeding. Compared with those in the control group, the adult zebrafish in all the four treatment groups exhibited significant increases in the activity of GK. The activity of PK was also significantly enhanced, except for that in the FF-3 group. The activity of G6Pase (Fig. 3(C)) was significantly decreased in only the FF-5 group. A significant decrease in the activity of PEPCK was observed in the FF-5 and YE-5 groups (Fig. 3(D)). The activity of intestinal AMY (Fig. 3(E)) was significantly enhanced in the FF-3 group than in the control group.

\section{Discussion}

In humans, nutritional and metabolic exposure during critical periods of early development can have a long-term programming effect in adulthood ${ }^{(29)}$. The same conclusions have been reached for rats ${ }^{(30)}$. Based on this concept, we carried out a study on potential nutritional programming in zebrafish. The goals of the study were to determine the effects of early short-term nutritional programming on growth, blood glucose levels, and hepatic and intestinal gene expression and activities of enzymes in zebrafish during a sensitive period and to determine potential long-term persistent metabolic changes in carbohydrate utilisation in adult zebrafish.

\section{Effects of early-stage high-carbohydrate feeding on growth and gene expression}

A significant increase in the weight of the larvae of the FF-3 group than in that of the larvae of the control group was observed, which might be due to differences in the ability to digest and metabolise dietary carbohydrates. In these early stages, the pancreatic enzymes (proteases, lipases and glucosidases) along with enterocyte cytosolic proteases are responsible for the digestive capacity ${ }^{(31)}$. Some scholars believe that there is a close relationship between carbohydrates and feeding habit than between proteins and feeding habit during the early larval stages ${ }^{(32-34)}$. Panserat et al. ${ }^{(35)}$ also found that carp larvae are capable of utilising dietary carbohydrates efficiently during the first-feeding stage. The body weight and length of the larvae of the control group increased gradually after hatching as did the growth rate (from 6 to $66 \%$ ). These results are in agreement with those of a study that used a novel method for rearing first-feeding zebrafish larvae ${ }^{(36)}$ and imply that the transition to the external feeding stage is accompanied by a drastic change in digestive and metabolic capacities to ensure efficient utilisation of exogenous feed ${ }^{(37)}$. When yolk nutrients are no longer sufficient to support the metabolic demand of the larvae, they must initiate exogenous feeding. However, zebrafish larvae exhibited an adverse trend in body weight and length when fed the high-carbohydrate diets.

We observed changes in the expression of $A M Y$ gene in the FF-3 and FF-5 groups, with the high-carbohydrate diets inducing 4-fold and about 2-fold increases compared with the 

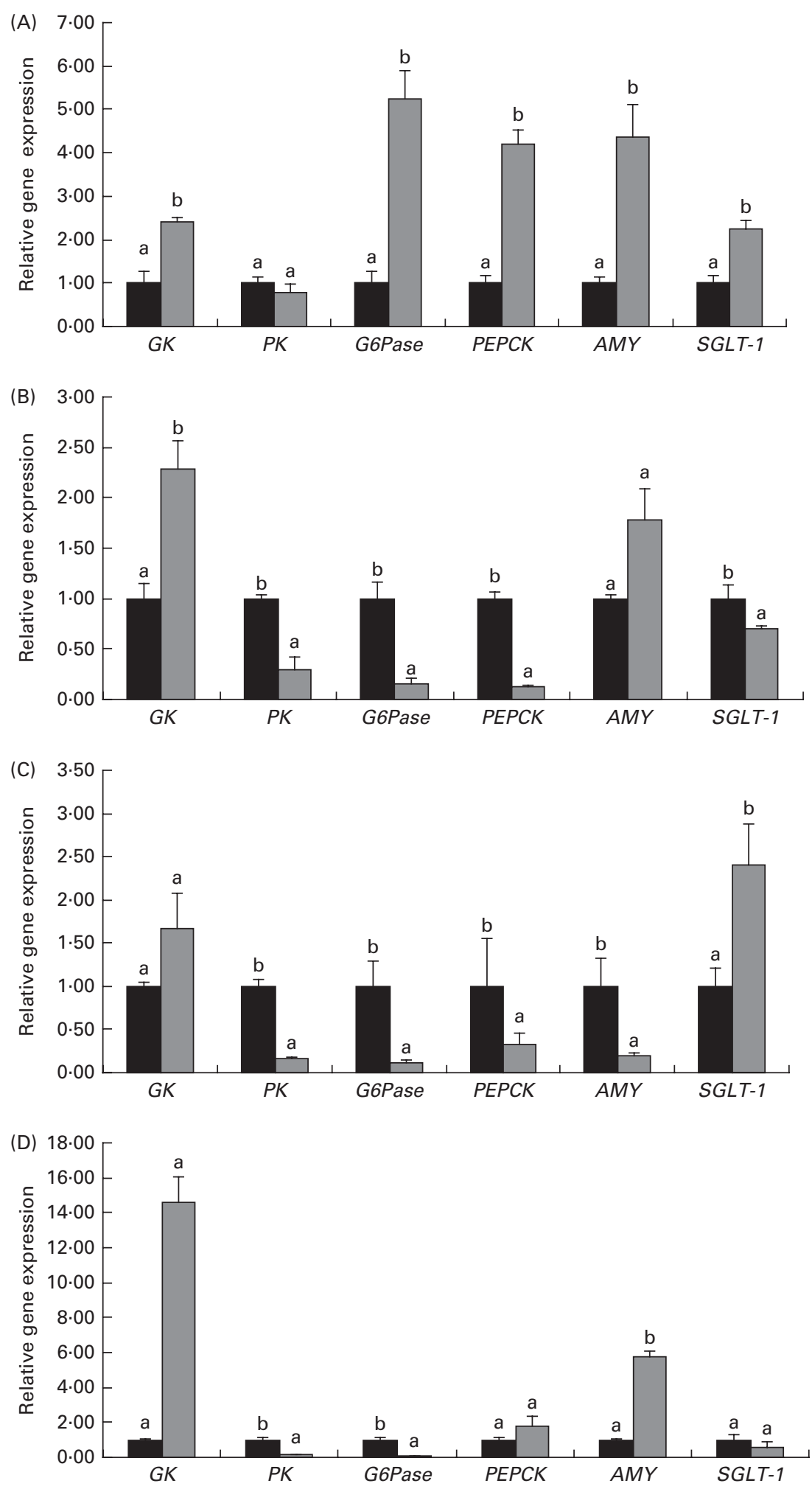

Fig. 1. Expression of six key genes in zebrafish larvae fed high-carbohydrate diets at different stages. GK, glucokinase; $P K$, pyruvate kinase; G6Pase, glucose-6phosphatase; PEPCK, phosphoenolpyruvate carboxykinase; $A M Y, \alpha$-amylase; SGLT-1, sodium-dependent glucose co-transporter 1. Control (口): fish fed the commercial diet; (A) FF-3 ( $\square$ ): fish fed the $60 \%$ maltodextrin diet from the first-feeding stage to the end of the yolk-sac larval stage; (B) FF-5 ( $\square$ ): fish fed the $60 \%$ maltodextrin diet from the first-feeding stage to $2 \mathrm{~d}$ after yolk-sac exhaustion; (C) YE-3 (ㅁ): fish fed the $60 \%$ maltodextrin diet after yolk-sac exhaustion for $3 \mathrm{~d}$; (D) YE-5 ( $\square$ ): fish fed the $60 \%$ maltodextrin diet after yolk-sac exhaustion for 5 d. Expression results were normalised to $\beta$-actin expression, which did not change with treatment. Values are means $(n 6)$, with their standard errors represented by vertical bars. ${ }^{a, b}$ Mean values of the carbohydrate dietary treatment fish with unlike letters were significantly different from those of the control fish $(P<0.05$; one-way ANOVA and Duncan's multiple range tests). 


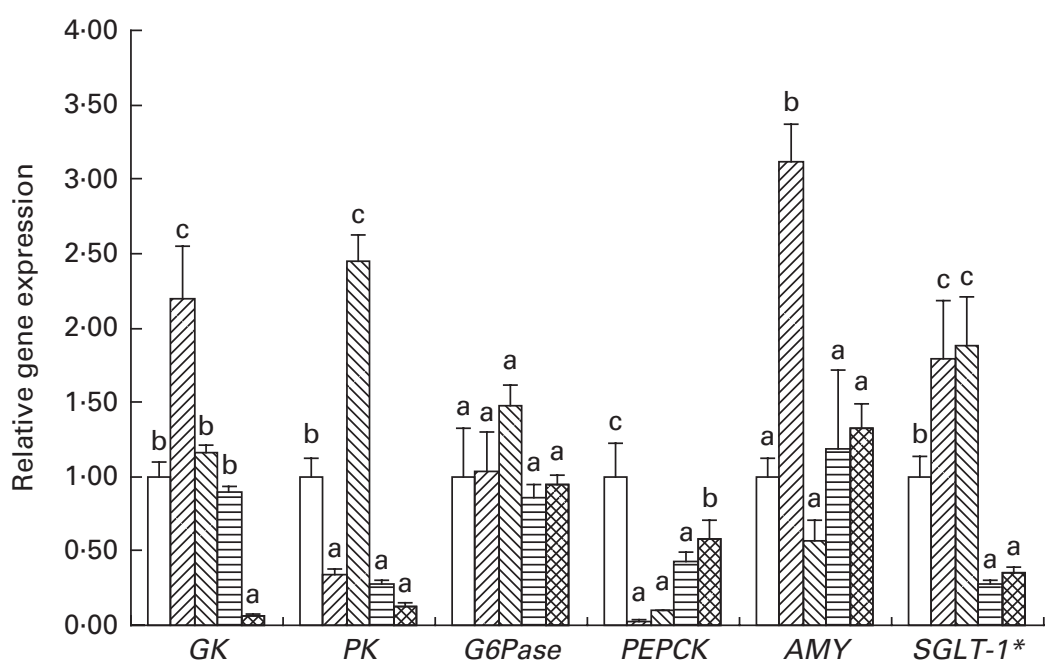

Fig. 2. Long-term effect of early high-carbohydrate stimuli on hepatic and intestinal gene expression in adult zebrafish (16-week feeding experiments). Control

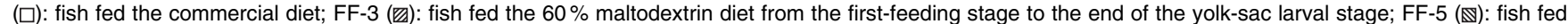
the $60 \%$ maltodextrin diet from the first-feeding stage to $2 \mathrm{~d}$ after yolk-sac exhaustion; YE-3 (目): fish fed the $60 \%$ maltodextrin diet after yolk-sac exhaustion for $3 \mathrm{~d}$; YE-5 (國): fish fed the $60 \%$ maltodextrin diet after yolk-sac exhaustion for $5 \mathrm{~d}$. Transcript levels of target genes were normalised to those of $\beta$-actin. Except the expression analysis of $S G L T-1^{*}$ gene carried out on total RNA extracted from intestinal tissue samples, expression analyses of other genes were carried out on total RNA extracted from liver tissue samples. Values are means $(n 6)$, with their standard errors represented by vertical bars. Statistical differences in gene expression between the samples were evaluated as means with their standard errors. ${ }^{a, b, c}$ Mean values with unlike letters were significantly different among the groups $(P<0.05$; one-way ANOVA and Duncan's multiple range tests). GK, glucokinase; $P K$, pyruvate kinase; G6Pase, glucose-6-phosphatase; $P E P C K$, phosphoenolpyruvate carboxykinase; $A M Y, \alpha$-amylase; SGLT-1, sodium-dependent glucose co-transporter 1.

control diet. These increases were induced due to the MD content of the carbohydrate diets. This was consistent with the results of a study carried out in rainbow trout ${ }^{(19)}$. However, the expression of $A M Y$ gene exhibited a significant decrease in the YE-3 group and subsequently an increase in the YE-5 group. Similar results were obtained by other authors for Asian sea bass (Dicentrarchus labrax), winter flounder (Pseudopleuronectes americanus) and mudskipper (Boleophthalmus pectinirostris) $^{(38-40)}$. Douglas et al. ${ }^{(40)}$ showed that $A M Y$ transcript levels increased at approximately day 20 and then decreased during metamorphosis in the winter flounder. Moreover, this decrease in $A M Y$ transcript levels is observed irrespective of the dietary carbohydrate concentration $^{(41)}$, suggesting that the decrease in AMY activity during larval development is genetically programmed. A study carried out in the mudskipper ${ }^{(39)}$ has also reported that AMY activity is higher in the larval stage, decreases drastically in the juvenile stage, and increases rapidly in the early young stage. This particular change in AMY activity may reflect different nutrient requirements at different stages in life.

Dietary glucose is transported into the lumen of the small intestine across the brush border membrane by SGLT- 1 and then across the basolateral membrane into the blood by GLUT2 ${ }^{(42)}$. Both SGLT-1 and GLUT2 are up-regulated by highcarbohydrate diets than by non-carbohydrate diets in the intestine of rainbow trout ${ }^{(43,44)}$. The high expression levels of SGLT-1 gene in the FF-3 and YE-3 groups were in line with observations in the omnivorous black bullhead (Ictalurus melas) $^{(45)}$, in which an increase in both apical and basolateral membrane glucose transport with high-carbohydrate diets has been reported. However, the dietary up-regulation of the expression of $S G L T-1$ gene observed from the first-feeding to the external feeding stage (FF-5) was not amplified by the early nutritional stimulus. The transcription of SGLT-1 in zebrafish larvae in the early stages was not fully expected, because dietary adaptation of intestinal glucose transport normally appears to be determined by the potential variation in carbohydrate supply of the natural diet of the organism ${ }^{(15,16)}$.

The enhanced transcription of $G K$, the first enzyme of glycolysis, in the larvae of the four treatment groups indicates that zebrafish adapt rapidly to the utilisation of exogenous glucose in the early stages. These results are clearly in agreement with those of previous studies carried out in rainbow trout and carp (C. carpio) larvae ${ }^{(19,46)}$. These findings in fish larvae indicate that the appearance of the GK enzyme is not developmentally determined but is controlled by the presence of a nutritional stimulus. In contrast, low $P K$ transcript levels were found in the four treatment groups. PK is another key glycolytic enzyme that catalyses the last step in glycolysis ${ }^{(11)}$. Cowey et $a l .{ }^{(47)}$ reported that an intraperitoneal injection of insulin has no effect on the activity of hepatic PK in rainbow trout fed a high-carbohydrate diet. More recently, PlagnesJuan $e t a l .{ }^{(48)}$ have also reported that insulin administration has no effect on the expression of $P K$ gene in rainbow trout. Another possible reason is linked to post-transcriptional regulation $^{(43)}$. There is less information on the molecular regulation of PK during early development in fish. Therefore, further studies are needed to address the expression of $P K$ gene in fish larvae.

One of the principal parameters affecting endogenous glucose output is the availability of gluconeogenic substrates ${ }^{(49)}$. In the present study, high expression levels of G6Pase and 

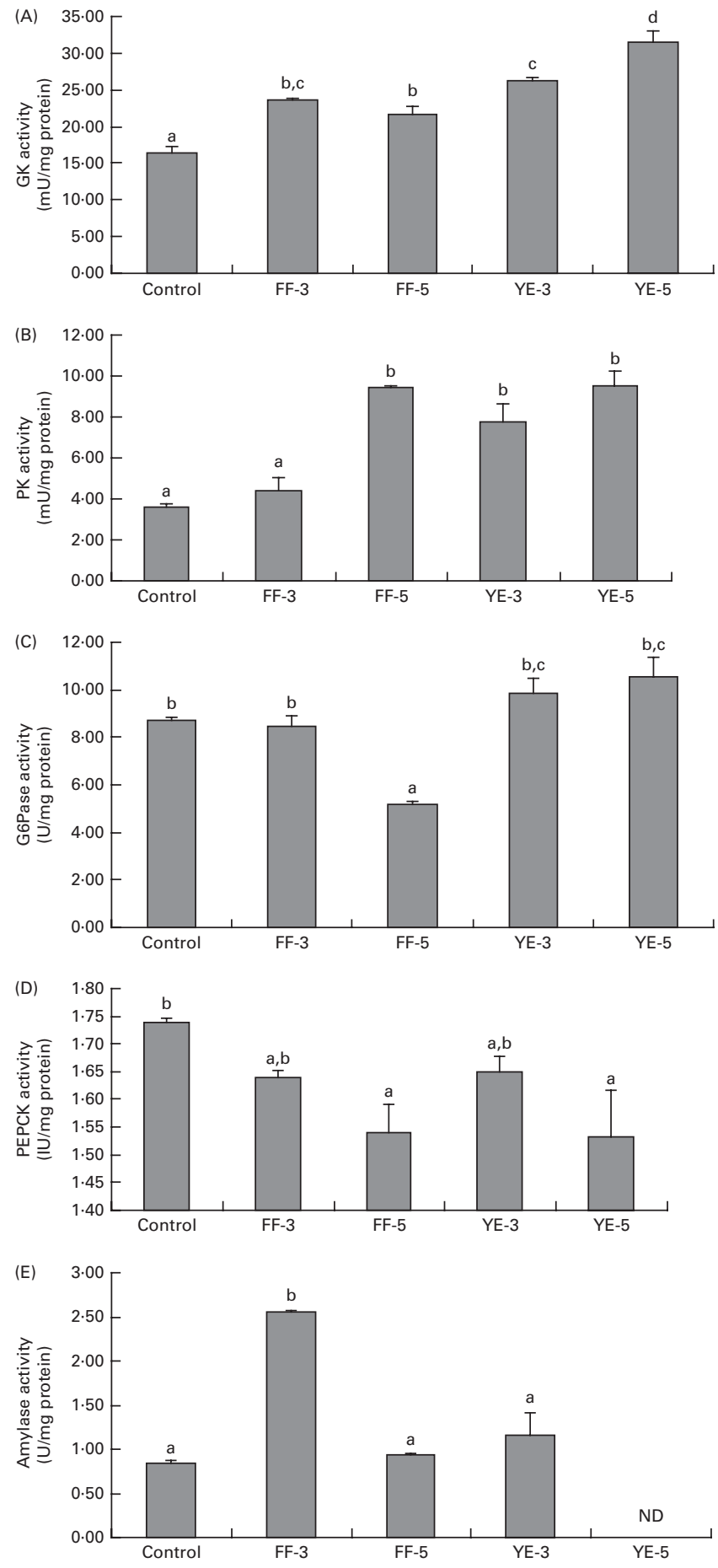

Fig. 3. Activities of five key enzymes in adult zebrafish $3 \mathrm{~h}$ after the last feeding (A) Glucokinase (GK); (B) pyruvate kinase (PK); (C) phosphoenolpyruvate carboxykinase (PEPCK); (D) glucose-6-phosphatase (G6Pase); (E) $\alpha$-amylase activities. The activities of these enzymes were determined using liver tissue samples. ND means no data. Values are means ( $n 6$ fish per treatment and time), with their standard errors represented by vertical bars. ${ }^{a, b, c, d}$ Mean values with unlike letters were significantly different among the groups $(P<0.05$; oneway ANOVA and Duncan's multiple range tests). Control group, fish fed the commercial diet; FF-3, fish fed the $60 \%$ maltodextrin diet from the first-feeding stage to the end of the yolk-sac larval stage; FF-5, fish fed the $60 \%$ maltodextrin diet from the first-feeding stage to $2 \mathrm{~d}$ after yolk-sac exhaustion; YE-3, fish fed the $60 \%$ maltodextrin diet after yolk-sac exhaustion for $3 \mathrm{~d}$; YE-5, fish fed the $60 \%$ maltodextrin diet after yolk-sac exhaustion for $5 \mathrm{~d}$.
PEPCK genes were found before the initiation of exogenous feeding. Data obtained for the FF-3 group suggest that this induction is mainly due to the catabolism of the vitelline reserves. After this stage, the expression of these two genes was markedly inhibited by the high-carbohydrate diets. These results are in agreement with the failure of dietary carbohydrates to suppress glucose output in rainbow trout observed at the later stage of first-feeding development ${ }^{(19)}$. The inhibition of the expression of G6Pase and PEPCK genes induced after the start of exogenous feeding shows the capacity of the fish larvae to carry out glycaemic regulation and to act on the presence of exogenous glucose.

\section{Long-term effects of early high-carbohydrate feeding in adult zebrafish}

In mammals, metabolic programming is an 'adaptive process' that occurs in response to a nutritional stimulus during an early sensitive period of life ${ }^{(50)}$. In the present study, highcarbohydrate diet feeding during the larval stages was used to metabolically programme the fish. We determined whether the short-term physiological plasticity towards dietary carbohydrates observed at the early feeding stage in the fish would persist in the adult stage. There was no negative effect of the early acute nutritional stimuli on the growth or survival of the adult zebrafish. After the 16-week experiment, the difference in body weight and length disappeared in the adult zebrafish, despite a significant difference in initial weight and length during the larval stages, in line with the results of previous studies carried out in rainbow trout ${ }^{(19)}$. These findings suggest that early dietary interventions do not influence the health status of the fish. On the other hand, a high-condition factor was observed in the FF-5 group, which experienced transition from the polyculture to the external feeding stage, suggesting that the physiological conditions of adult fish can be improved during this particular ontogenetic phase ${ }^{(51)}$.

It is well known that if carbohydrates are given in excess, glucose intolerance and metabolic burden may result in teleost fish $^{(9)}$. In fact, several studies have shown that high levels of dextrin in diets lead to constantly high blood sugar levels ${ }^{(52)}$. In the present study, however, plasma glucose levels of the treatment groups tended to decrease compared with those of the control group. This indicates that glucose uptake into tissues and glucose phosphorylation levels of the treatment groups might be improved. However, plasma glucose levels of rainbow trout have been shown to be unaffected by a history of early carbohydrate feeding ${ }^{(19)}$, suggesting that omnivorous fish may have glucose homeostasis mechanisms that allow then to metabolically adapt to dietary glucose. The reason for this may probably be the differences in dietary glucose loading and feeding habits. Since fish represent the most diverse and primitive group of vertebrates ${ }^{(53)}$, this finding may serve as a useful reference point for comparative studies in other vertebrates.

The present results indicate that although dietary glucose is a partial inducer of the expression of the $G K$ gene, the activity of the GK enzyme increases during rapid adaptation in this species as in mammals ${ }^{(54)}$. Although the expression levels of $G K$ gene were low, except in the FF-3 group, the activity of GK enzyme 
was highly induced. This induction may result from a simple translocation from a regulatory protein. It is worth noting that glycaemia was rapidly suppressed when the levels of GK enzyme increased, suggesting that GK protein is important for glucose homeostasis control in fish. No changes in the expression of $P K$ gene were observed in the adult zebrafish as in the larvae. The stability of $P K$ gene is a crucial factor in regulation at the translational level in mammals ${ }^{(55)}$. The present results suggest that $P K$ transcripts might remain relatively steady due to the characteristics of the inherent molecules. However, the hepatic mRNA levels and activity of PK increased in lockstep in the FF-5 group. The reason for this could be the effective adaptation to the carbohydrate diets from the polyculture to the external feeding stage.

Several studies carried out in fish have indicated that the expression and enzyme activity of G6Pase are not suppressed by dietary carbohydrates, suggesting a low flexibility of gluconeogenesis in various teleosts ${ }^{(19,46,56-58)}$. However, the activity of G6Pase enzyme was decreased in the FF-5 group by the carbohydrate diets. This finding suggests that the transition period from the polyculture to the external feeding stage is very important for the adaptation of this enzyme. It has been shown that both gene expression and activity of this important gluconeogenic enzyme are independent of carbohydrate-rich diet intake ${ }^{(43,54,56)}$. The expression of PEPCK gene was significantly decreased with high-carbohydrate feeding, and the activity of PEPCK enzyme was also decreased to a greater extent, significantly in the FF- 5 and YE- 5 groups. These results suggest that early carbohydrate-rich dietary intervention could significantly affect the transcription levels of $P E P C K$ gene in adult zebrafish, which can effectively inhibit gluconeogenesis. Taken together, these data suggest that the gluconeogenic pathway is tightly controlled by dietary carbohydrates with early nutritional programming from the polyculture to the external feeding stage.

Rainbow trout exposed to early short-term highcarbohydrate stimuli have been shown to exhibit high expression of $A M Y$ gene in the adult stage ${ }^{(19)}$. Interestingly, the data obtained for zebrafish in the first-feeding stage in the present study were similar to those obtained for the carnivorous rainbow trout. This demonstrates that the transcription levels of this gene are significantly affected by early high-carbohydrate interventions in these two fish species. The expression levels of SGLT-1 gene can also be affected by the treatment during the early first-feeding period. This will play a very large role in glucose transport ${ }^{(5)}$ in the adult stage when fish are fed high-carbohydrate diets. Further studies are needed to assess the protein content and intestinal tissue morphology to further validate the changes. Accordingly, these data support the idea of an efficient adaptation in dietary carbohydrate digestion and absorption in zebrafish when conditioned by nutritional stimuli during critical periods ${ }^{(50)}$.

\section{Conclusions}

In conclusion, the present study demonstrates that dietary nutritional programming during early sensitive periods induces efficient adaptation and potential capacity to utilise high-carbohydrate diets in adult zebrafish. In the larval stages, high-carbohydrate diets could promote growth from the first-feeding stage to the end of the yolk-sac larval stage. The expression of genes involved in carbohydrate digestion, transport and metabolism was differentially regulated by the early dietary intervention. In the adult stage, growth performance was not affected in any of the groups. As expected, plasma glucose levels exhibited greater degrees of decline when adult fish were fed high-carbohydrate diets. Furthermore, our findings do confirm that the period ranging from the polyculture to the external feeding stage is important for early programming of the high-carbohydrate nutritional adaptation to persist into the adult stage. This newly emerging field of early nutritional programming offers a novel route to improve research and management in areas of applied science, such as aquaculture, fisheries and environmental assessment, with regard to glucose excretion.

\section{Acknowledgements}

The authors are grateful to Bin Li, Jiao Li, Yan Xu and Wenjing Zhang for their technical assistance. They also cordially thank Dr Liang Cao for his help in editing the references.

The present study was financially supported by the National Natural Science Foundation of China (31172420 and 31072219), the National Basic Research Program of China (2009CB118702 and 2014CB138601), the Special Fund for Agro-Scientific Research in the Public Interest of China (201003020) and the Fundamental Research Funds for the Central Universities (2010PY010 and 2011PY030) (to X.-F. L). The funders contributed to the design of the study, interpretation of the findings and preparation of the manuscript.

The authors' contributions were as follows: X.-F. L., L. F. and Y. H. designed the study and interpreted the findings; L. F., Y. Z. and X.-Z. G. carried out the laboratory analyses; L.-W. L. and X.-C. Y were responsible for the rearing of fish; T.-L. Y. prepared the feeds; L. F. and Y. Z. analysed the data; L. F., X.-F. L. and Y.-X. T. wrote the manuscript; X.-F. L. and Y. H. were the project leaders.

None of the authors has any conflicts of interest.

\section{References}

1. Wilson RP (1994) Utilisation of dietary carbohydrate by fish. Aquaculture 124, 67-80.

2. Kim J \& Kaushik S (1992) Contribution of digestible energy from carbohydrates and estimation of protein/energy requirements for growth of rainbow trout (Oncorbynchus mykiss). Aquaculture 106, 161-169.

3. Grisdale-Helland B \& Helland S (1997) Replacement of protein by fat and carbohydrate in diets for atlantic salmon (Salmo salar) at the end of the freshwater stage. Aquaculture 152, $167-180$.

4. Cowey CB \& Walton MJ (1989) Intermediary metabolism. In Fish Nutrition, pp. 259-329 [JE Halver, editor]. San Diego, NY: Academic Press.

5. Krogdahl A, HEMRE GI \& Mommsen T (2005) Carbohydrates in fish nutrition: digestion and absorption in postlarval stages. Aquacult Nutr 11, 103-122. 
6. Jantrarotai W, Sitasit P, Jantrarotai $\mathrm{P}$, et al. (2007) Protein and energy levels for maximum growth, diet utilization, yield of edible flesh and protein sparing of hybrid Clarias catfish (Clarias macrocephalus $\times$ Clarias gariepinus). I World Aquacult Soc 29, 281-289.

7. Deng D, Refstie S, Hemre GI, et al. (2000) A new technique of feeding, repeated sampling of blood and continuous collection of urine in white sturgeon. Fish Physiol Biochem 22, 191-197.

8. Palmer TN \& Ryman BE (1972) Studies on oral glucose intolerance in fish. J Fish Biol 4, 311-319.

9. Hemre GI, Mommsen T \& Krogdahl A (2002) Carbohydrates in fish nutrition: effects on growth, glucose metabolism and hepatic enzymes. Aquacult Nutr 8, 175-194.

10. Panserat S, Médale F, Blin C, et al. (2000) Hepatic glucokinase is induced by dietary carbohydrates in rainbow trout, gilthead seabream, and common carp. Am J Physiol Regul Integr Comp Physiol 278, R1164-R1170.

11. Enes P, Panserat S, Kaushik S, et al. (2009) Nutritional regulation of hepatic glucose metabolism in fish. Fish Physiol Biochem 35, 519-539.

12. Pilkis S \& Granner D (1992) Molecular physiology of the regulation of hepatic gluconeogenesis and glycolysis. Annu Rev Physiol 54, 885-909.

13. Kirchner S, Panserat S, Lim PL, et al. (2008) The role of hepatic, renal and intestinal gluconeogenic enzymes in glucose homeostasis of juvenile rainbow trout. $J$ Comp Physiol B 178, 429-438.

14. Ferraris RP \& Diamond JM (1993) Crypt/villus site of substrate-dependent regulation of mouse intestinal glucose transporters. Proc Natl Acad Sci U S A 90, 5868-5872.

15. Péres A, Zambonino Infante J \& Cahu C (1998) Dietary regulation of activities and mRNA levels of trypsin and amylase in sea bass (Dicentrarchus labrax) larvae. Fish Physiol Biochem 19, $145-152$

16. Geurden I, Aramendi M, Zambonino-Infante J, et al. (2007) Early feeding of carnivorous rainbow trout (Oncorbynchus mykiss) with a hyperglucidic diet during a short period: effect on dietary glucose utilization in juveniles. Am J Physiol Regul Integr Comp Physiol 292, R2275-R2283.

17. Lucas A (1998) Programming by early nutrition: an experimental approach. J Nutr 128, 401S-406S.

18. Ulloa PE, Iturra P, Neira R, et al. (2011) Zebrafish as a model organism for nutrition and growth: towards comparative studies of nutritional genomics applied to aquacultured fishes. Rev Fish Biol Fisher 21, 649-666.

19. Aleström P, Holter JL \& Nourizadeh-Lillabadi R (2006) Zebrafish in functional genomics and aquatic biomedicine. Trends Biotechnol 24, 15-21.

20. Dahm R \& Geisler R (2006) Learning from small fry: the zebrafish as a genetic model organism for aquaculture fish species. Mar Biotechnol 8, 329-345.

21. Hensley MR \& Leung YF (2010) A convenient dry feed for raising zebrafish larvae. Zebrafish 7, 219-231.

22. Ng ANY, de Jong-Curtain TA, Mawdsley DJ, et al. (2005) Formation of the digestive system in zebrafish: III. Intestinal epithelium morphogenesis. Dev Biol 286, 114-135.

23. Polakof S \& Soengas JL (2008) Involvement of lactate in glucose metabolism and glucosensing function in selected tissues of rainbow trout. J Exp Biol 211, 1075-1086.

24. Gaxiola G, Cuzon G, García T, et al. (2005) Factorial effects of salinity, dietary carbohydrate and moult cycle on digestive carbohydrases and hexokinases in Litopenaeus vannamei (Boone, 1931). Comp Biochem Physiol A 140, 29-39.

25. Kirchner S, Seixas P, Kaushik S, et al. (2005) Effects of low protein intake on extra-hepatic gluconeogenic enzyme expression and peripheral glucose phosphorylation in rainbow trout (Oncorbynchus mykiss). Comp Biochem Physiol B 140, 333-340.

26. Pang Y \& Ge W (2002) Gonadotropin and activin enhance maturational competence of oocytes in the zebrafish (Danio rerio). Biol Reprod 66, 259-265.

27. Livak KJ \& Schmittgen TD (2001) Analysis of relative gene expression data using real-time quantitative PCR and the $2^{-\Delta \Delta C_{\mathrm{t}}}$ method. Methods 25, 402-408.

28. Morgan GA, Leech NL, Gloeckner GW, et al. (2004) SPSS for Introductory Statistics: Use and Interpretation. Mahwah, NJ: Lawrence Erlbaum Associates.

29. Demmelmair H, von Rosen J \& Koletzko B (2006) Long-term consequences of early nutrition. Early Hum Dev 82, $567-574$

30. Hall WG (1975) Weaning and growth of artificially reared rats. Science 190, 1313.

31. Zambonino Infante J \& Cahu C (2001) Ontogeny of the gastrointestinal tract of marine fish larvae. Comp Biochem Physiol C 130, 477-487.

32. Hidalgo M, Urea E \& Sanz A (1999) Comparative study of digestive enzymes in fish with different nutritional habits Proteolytic and amylase activities. Aquaculture 170, 267-283.

33. Kapoor B, Smit H \& Verighina I (1976) The alimentary canal and digestion in teleosts. Adv Mar Biol 13, 109-239.

34. Fan X, Klein M, Flanagan-Steet HR, et al. (2010) Selective yolk deposition and mannose phosphorylation of lysosomal glycosidases in zebrafish. J Biol Chem 285, 32946-32953.

35. Panserat S, Fontagnéa S, Bergota P, et al. (2001) Ontogenesis of hexokinase I and hexokinase IV (glucokinase) gene expressions in common carp (Cyprinus carpio) related to diet. Br J Nutr 85, 649-651.

36. Best J, Adatto I, Cockington J, et al. (2010) A novel method for rearing first-feeding larval zebrafish: polyculture with type L saltwater rotifers (Brachionus plicatilis). Zebrafish $\mathbf{7}$, 289-295.

37. Hoehne-Reitan K \& Kjorsvik E (2004) Functional development of the liver and exocrine pancreas in teleost fish. Am Fish Soc Symp 40, 9-36.

38. Cahu C \& Infante J (1994) Early weaning of sea bass (Dicentrarchus labrax) larvae with a compound diet: effect on digestive enzymes. Comp Biochem Physiol A 109, 213-222.

39. Wu RX, Hong WS, Zhang QY, et al. (2006) Digestive enzyme activities in larval, juvenile and early young fish of Boleophthalmus pectinirostris. J Fish China 30, 733-739.

40. Douglas SE, Mandla S \& Gallant JW (2000) Molecular analysis of the amylase gene and its expressionduring the development in the winter flounder Pleuronectes americanus. Aquaculture 190, 247-260.

41. Peres A, Cahu CL, Zambonino Infante JL, et al. (1996) Amylase and trypsin responses to intake of dietary carbohydrate and protein depend on the developmental stage in sea bass Dicentrarchus labrax larvae. Fish Physiol Biochem 15, 237-242.

42. Ferraris RP (2001) Dietary and developmental regulation of intestinal sugar transport. Biochem J 360, 265-276.

43. Panserat S, Plagnes-Juan E \& Kaushik S (2001) Nutritional regulation and tissue specificity of gene expression for proteins involved in hepatic glucose metabolism in rainbow trout (Oncorbynchus mykiss). J Exp Biol 204, 2351-2360.

44. Sugiura SH, McDaniel NK \& Ferraris RP (2003) In vivo fractional $\mathrm{Pi}$ absorption and NaPi-II mRNA expression in rainbow trout are upregulated by dietary $\mathrm{P}$ restriction. $A m$ J Physiol Regul Integr Comp Physiol 285, R770-R781.

45. Soengas JL \& Moon TW (1998) Transport and metabolism of glucose in isolated enterocytes of the black bullhead 
Ictalurus melas: effects of diet and hormones. J Exp Biol 201, 3263-3273.

46. Panserat S, Capilla E, Gutierrez J, et al. (2001) Glucokinase is highly induced and glucose-6-phosphatase poorly repressed in liver of rainbow trout (Oncorbynchus mykiss) by a single meal with glucose. Comp Biochem Physiol B 128, 275-283.

47. Cowey CB, Knox D, Walton MJ, et al. (1977) The regulation of gluconeogenesis by diet and insulin in rainbow trout (Salmo gairdneri). Br J Nutr 38, 463-470.

48. Plagnes-Juan E, Lansard M, Seiliez I, et al. (2008) Insulin regulates the expression of several metabolism-related genes in the liver and primary hepatocytes of rainbow trout (Oncorbynchus mykiss). J Exp Biol 211, 2510-2518.

49. Barthel A \& Schmoll D (2003) Novel concepts in insulin regulation of hepatic gluconeogenesis. Am J Physiol Endocrinol Metab 285, E685-E692.

50. Patel MS \& Srinivasan M (2002) Metabolic programming: causes and consequences. J Biol Chem 277, 1629-1632.

51. Bolger T \& Connolly P (1989) The selection of suitable indices for the measurement and analysis of fish condition. J Fish Biol 34, 171-182.

52. Hemre G, Sandnes K \& Waagbø R (1995) Blood chemistry and organ nutrient composition in Atlantic salmon, Salmo salar L., fed graded amounts of wheat starch. Aquacult Nutr 1, 37-42.

53. Wang Y \& Ge W (2003) Involvement of cyclic adenosine $3^{\prime}, 5^{\prime}$-monophosphate in the differential regulation of activin $\beta \mathrm{A}$ and $\beta \mathrm{B}$ expression by gonadotropin in the zebrafish ovarian follicle cells. Endocrinology 144, 491-499.

54. Printz RL, Magnuson MA \& Granner DK (1993) Mammalian glucokinase. Annu Rev Nutr 13, 463-496.

55. Yamada K \& Noguchi T (1999) Nutrient and hormonal regulation of pyruvate kinase gene expression. Biochem $J$ 337, 1-11.

56. Panserat S, Médale F, Breque J, et al. (2000) Lack of significant long-term effect of dietary carbohydrates on hepatic glucose-6-phosphatase expression in rainbow trout (Oncorbynchus mykiss). J Nutr Biochem 11, 22-29.

57. Caseras A, Metón I, Vives C, et al. (2002) Nutritional regulation of glucose-6-phosphatase gene expression in liver of the gilthead sea bream (Sparus aurata). Br J Nutr 88, 607-614.

58. Panserat S, Plagnes-Juan E, Breque J, et al. (2001) Hepatic phosphoenolpyruvate carboxykinase gene expression is not repressed by dietary carbohydrates in rainbow trout (Oncorbynchus mykiss). J Exp Biol 204, 359-365. 